\title{
Use of Prophylactic Indomethacin in Preterm Infants: A Systematic Review and Meta-analysis
}

Abdulrahman Al matary ( $\sim$ amatry@yahoo.com )

King Fahad Medical City Riyadh

\section{Research article}

Keywords: Prophylactic Indomethacin, necrotizing enterocolitis, mortalities

Posted Date: November 23rd, 2020

DOl: https://doi.org/10.21203/rs.3.rs-111839/v1

License: @ (i) This work is licensed under a Creative Commons Attribution 4.0 International License. Read Full License 


\section{Abstract}

Background

Prophylactic indomethacin has been widely used as an effective intervention for reducing mortalities and morbidities in preterm infants including the cardiopulmonary and neurodevelopmental morbidities as intraventricular hemorrhage (IVH), but many studies have reported contraindicated outcomes of its significance. Therefore, we aim to systematically review and meta-analyze the data of prophylactic indomethacin on preterm infants.

Methods

Our systematic search included the following databases: Pubmed, Google Scholar, Scopus, Web of Science, The New York Academy of Medicine (NYAM), Virtual health library (VHL), and the System for Information on Grey Literature in Europe (SIGLE) to include studies that assessed the use of prophylactic indomethacin in preterm infants until August 12, 2020.

Results

The final list of our included studies is comprised of 22 randomized trials and cohort studies. Our analysis of observational data showed that intubation in the delivery room/first day (74\%), bronchopulmonary dysplasia (BPD) (33.2\%), and patent ductus arteriosus (PDA) (32.2\%) were the most prevalent outcomes in infants that received prophylactic indomethacin. Among all the studies outcomes, the only significant favorable outcome was lowering the rate of PDA ( $<<$ 0.001) while no significance was recorded with BPD, pulmonary hemorrhage, neurodevelopmental delays (IVH), mortality, length of hospital stays, and time spent on ventilators outcomes $(P=0.106,0.123,0.460,0.340,0.625$, and 0.732 , respectively). Moreover, necrotizing enterocolitis was significantly increased when applying prophylactic indomethacin in these infants $(P<0.001)$.

Conclusion

The use of prophylactic indomethacin in preterm infants should be generally discouraged due to its neutral effect on most of the mortality and morbidity outcomes and the significant occurrence of its adverse events despite the positive effect on ductal closure.

\section{Structured Summary}

\section{Background}

Many authors believe neurologic disabilities have been associated with preterm labor presumed due to either over circulation or under circulation secondary to patent ductus arteriosus.

\section{Objectives}

Systemically revied all published RCT and meta-analysis to find if prophylactic indomethacin can decrease CNS complications.

\section{Data sources}

Following the Preferred Reporting Items for Systematic Review and Meta-analyses statement (PRISMA) recommendations, we performed this systematic review and meta-analysis (32). A systematic electronic database search was conducted for relevant studies published, from inception to 12th August 2020, in seven databases: Pubmed, Google Scholar, Scopus, Web of Science, The New York Academy of Medicine (NYAM), Virtual health library (VHL), and the System for Information on Grey Literature in Europe (SIGLE).

\section{Study eligibility criteria, participants, and interventions}

Participants were any preterm infants, the intervention was the prophylactic indomethacin, the comparison was placebo or no treatment groups, and all possible outcomes were included. The systematic search was followed by a manual search in references of the included papers to include missed papers. We included all original studies that assessed the use of prophylactic indomethacin in preterm infants.

Papers were excluded if there were one of the following exclusion criteria:

I. non-original studies

II. in vitro or animal studies;

III. data duplication, overlapping or unreliably extracted or incomplete data;

IV. abstract only articles, reviews, thesis, books, conference papers, or articles without available full texts (conferences, editorials, author response, letters, and comments.

\section{Risk of bias}

The revised Cochrane quality assessment tool (RoB 2) was used to determine the quality of randomized studies and the risk of bias in non-randomized studies - of interventions (ROBINS-I) tool for non-randomized studies.

\section{Data analysis}


All data were analyzed using R software version 4.0.2. Using the "meta" package, odds ratios (OR) and prevalence rates of different outcomes were calculated. The corresponding $95 \%$ confidence intervals $(\mathrm{Cl})$ of pooled effect size were calculated using a fixed-effects or random-effects, according to heterogeneity level. Heterogeneity was assessed with Q statistics and I2 test considering it significant with I2 value $>50 \%$ or P-value $<0.05$.

The publication bias was assessed using Egger's regression test and represented graphically by Begg's funnel plot when there were ten or more studies/effect sizes. Egger's regression test P-value $<0.10$ was considered significant. Whenever publication bias was found, the trim and fill method of Duvall and Tweedie was applied to add studies that appeared to be missing to enhance the symmetry.

\section{Limitations}

Limitations to our study include the significant heterogeneity in the analysis of some outcomes due to the different study designs that were included in this study. However, we estimated the risk of bias in most cases when significant heterogeneity was estimated, and no significant risk was found in these events.

\section{Conclusions}

Prophylactic indomethacin in VLBW infants has proven efficient in preventing short-term events as PDA. My analysis, however, showed no significance on IVH despite the many investigations that were published before which showed that indomethacin can reduce the incidence of IVH and other neurodevelopmental abnormalities.

\section{Implications of key findings}

I tried to lose the debate in this matter, so the clinician can work on other interventions or quality projects to help in decreasing CNS complications in preterm infants.

\section{Systematic review registration number}

We could not obtain because there are a big waiting list and priority for UK researchers.

\section{Background}

Many cardiopulmonary and neurologic disabilities have been associated with preterm labor including patent ductus arteriosus (PDA), pulmonary hemorrhage, intracranial hemorrhage, and mental retardation (1-4). Although advances in modern medicine have improved the survival rates of very low birth weight (VLBW) infants, many neurodevelopmental complications are still present due to preterm birth such as blindness, deafness, and cerebral palsy. VLBW infants are liable to intraventricular hemorrhage (IVH) which is usually associated with the neurodevelopmental decays when related to the brain parenchyma. IVH grade 3-4 is a major risk factor for the occurrence of these complications in preterm infants (5-8). Although the incidence rate of IVH has been markedly reduced since the 1980 s $(9,10)$, no or minimal reductions have been recorded recently $(11,12)$.

Many pre- and postnatal interventions have been reported to effectively treat IVH and reduce its incidence in preterm infants (13). One of these is indomethacin prophylaxis which is better administered within the first six hours after birth (14-17). Besides, it helps in the closure of ductus arteriosus and therefore, can prevent the complications of PDA as pulmonary hypertension $(14,15,18)$. Its mechanisms of action include prostaglandin synthesis inhibition by inhibiting the cyclooxygenase pathways, reduction of hyperemic responses resulting from cerebrovascular hypoxia and hypercapnia, increasing the bloodbrain barrier permeability, and prevention of cerebral perfusion-induced ischemia (19-23). Moreover, it enhances microvascular development in the germinal matrix (24). Perfusion-related factors as hypoxia, hypercapnia, and hypotension usually develop after birth in VLBW infants (25). Most cases of preterm infants develop IVH within 6-8 hours after birth regardless of the gestational age (26). It happens probably due to the increased levels of angiopoietin 2 and vascular endothelial growth factor in the germinal matrix that normally decreases within hours after birth (13).

The results of previously published randomized controlled trials (RCTs) have shown that early administration of indomethacin after birth lowers the incidence of symptomatic PDA and severe IVH as a prophylactic measurement $(16,27-29)$. Although indomethacin administration showed favorable outcomes in reducing IVH incidence, many concerns have aroused concerning its effect on cerebral perfusion $(30,31)$. The rates of mortalities, bronchopulmonary dysplasia (BPD), or long-term neurodevelopmental decays reportedly seem to have been not affected. A previously published large RCT advised against using indomethacin as a prophylactic agent (15). Although the study showed favorable outcomes in terms of reducing incidence rates of PDA, PDA ligation, IVH, and pulmonary hemorrhage, no improvement regarding the incidence of death and neurodevelopmental disorders rates has been found. Therefore, in this systematic review, we aim to analyze the data of previously published investigations on the use of prophylactic indomethacin in preterm infants.

\section{Methods}

\section{Search strategy and study selection}

In accordance with the Preferred Reporting Items for Systematic Review and Meta-analyses statement (PRISMA) recommendations, we performed this systematic review and meta-analysis (32). A systematic electronic database search was conducted for relevant studies published, from inception to $12^{\text {th }}$ August 2020, in seven databases: Pubmed, Google Scholar, Scopus, Web of Science, The New York Academy of Medicine (NYAM), Virtual health library (VHL), and the System for Information on Grey Literature in Europe (SIGLE). The search process conducted using keywords, medical subject (MeSH) terms, and publication types based on the PICO framework (participants, comparison, intervention, and outcomes). Participants were any preterm infants, the intervention was the prophylactic indomethacin, the comparison was placebo or no treatment groups, and all possible outcomes were included. The systematic search was followed by a manual search in references of the included papers to include missed papers (33).

Page $3 / 20$ 
We included all original studies that assessed the use of prophylactic indomethacin in preterm infants. Papers were excluded if there were one of the following exclusion criteria: i) non-original studies ii) in vitro or animal studies; iii) data duplication, overlapping or unreliably extracted or incomplete data; iv) abstract only articles, reviews, thesis, books, conference papers or articles without available full texts (conferences, editorials, author response, letters, and comments. The title and abstract screening were performed by four independent reviewers. Furthermore, three independent reviewers performed full-text screening to ensure the inclusion of relevant papers in our systematic review. Any disagreement was done by discussion and consulting the senior member when necessary.

\section{Data extraction}

Two authors made the pilot extraction of a few papers for building the data extraction sheet. The data extraction sheet included: patient's characteristics, outcomes, and risk of bias tool. Two authors extracted the data and reviewed by a third reviewer when necessary. If a disagreement occurs, a senior author was consulted.

\section{Risk of bias}

Three independent authors assessed the risk of bias among different included studies using the revised Cochrane quality assessment tool (RoB 2) was used to determine the quality of randomized studies (34) and the risk of bias in non-randomized studies - of interventions (ROBINS-I) tool for non-randomized studies (35). Any discrepancy between the reviewers was solved by discussion or in conjugation with the senior author.

\section{Statistical analysis}

All data were analyzed using R software version 4.0.2 (36). Using the "meta" package, odds ratios (OR) and prevalence rates of different outcomes were calculated (37). The corresponding $95 \%$ confidence intervals ( $\mathrm{Cl}$ ) of pooled effect size were calculated using a fixed-effects or random-effects, according to heterogeneity level. Heterogeneity was assessed with Q statistics and $\mathrm{I}^{2}$ test considering it significant with $\mathrm{I}^{2}$ value $>50 \%$ or $\mathrm{P}$-value $<0.05(38)$.

The publication bias was assessed using Egger's regression test $(39,40)$ and represented graphically by Begg's funnel plot $(41)$ when there were ten or more studies/effect sizes. Egger's regression test P-value $<0.10$ was considered significant. Whenever publication bias was found, the trim and fill method of Duvall and Tweedie was applied to add studies that appeared to be missing (42) to enhance the symmetry.

\section{Results}

\section{Search results}

We identified 3,801 records after excluding of 506 duplicates by using Endnote software version X9. Title and abstract screening resulted in 36 records for further full-text screening. The later yielded 20 eligible papers for inclusion in our study. Two papers were added after performing manual search trials. Finally, we included 22 studies for this systematic review and meta-analysis (Figure 1).

\section{Study characteristics and risk of bias}

Out of the 22 included studies; seven were randomized controlled trials and the remaining 15 were cohort in design. The sample size of the included studies was highly variable ranging from 19 and as high as 34,602 pre-term infants. The average mean age in all reported treatment groups was 28 weeks (ranging from 25 to 50 weeks), while it was 27 weeks in control ones (ranging from 26 to 29 weeks). Table 1 shows the main characteristics of the included studies.

The overall risk of bias in the included RCTs was low in more than $50 \%$ of all items. The domains with major problems were deviations from intended interventions, randomization processes, and missing outcome data (Figure 2). For non-randomized trials, the risk of bias was higher with more than $50 \%$ of all items showing serious of critical risks of bias. Domains with the biggest issues were deviations from intended interventions, selective reporting, and cofounding of the results (Figure 3).

\section{Cardiopulmonary Outcomes}

Eight studies, with a total of 20,708 preterm infants, were included in the analysis of patent ductus arteriosus (PDA) rates. Infants with prophylactic doses of indomethacin showed significantly lower rates of PDA compared to those who did not ( $\mathrm{OR}=0.33 ; 95 \% \mathrm{Cl}=0.27-0.39 ; \mathrm{P}$-value< 0.001$)$. However, there was significant heterogeneity among the included studies $\left(I^{2}=72 \%\right.$; P-value< 0.001$)$ (Figure 4).

In contrast, there was no significant differences among the two groups when compared in terms of $\mathrm{BPD}(\mathrm{OR}=1.08 ; 95 \% \mathrm{Cl}=0.98-1.18 ; \mathrm{P}-\mathrm{value}=106)$ and pulmonary hemorrhage rates $(\mathrm{OR}=0.84 ; 95 \% \mathrm{Cl}=0.67-1.05 ; \mathrm{P}$-value= 0.132$)$. There was no significant heterogeneity among the included studies for both $\mathrm{BPD}$ $\left(I^{2}=48 \%\right.$; P-value $\left.=0.121\right)$ and pulmonary hemorrhage $\left(I^{2}=0 \%\right.$; P-value= 0.786$)$ outcomes (Figure 4).

\section{Neuro-developmental Outcomes}

Nine studies, with 17,949 pre-term infants, and five studies, with 20,116 pre-term infants, were included in the analyses of IVH and cerebral palsy (CP)/neurodevelopmental delay outcomes, respectively. There were no significant differences between prophylactic indomethacin group and the placebo/no treatment group in terms of IVH $(\mathrm{OR}=0.90 ; 95 \% \mathrm{Cl}=0.69-1.18$; P-value= 0.460) and $\mathrm{CP} /$ neurodevelopmental delay $(\mathrm{OR}=1.00 ; 95 \% \mathrm{Cl}=0.81-1.23 ; \mathrm{P}-\mathrm{value}=$ 0.997). For heterogeneity, there was a significant heterogeneity in both analyses with $\left(I^{2}=84 \%\right.$; P-value $\left.<0.001\right)$ and $\left(I^{2}=76 \%\right.$; $P$-value $\left.=0.002\right)$ for IV and $\mathrm{CP} /$ neurodevelopmental delay, respectively (Figure 5). 


\section{Necrotizing enterocolitis/Intestinal perforation, and death}

Nine studies, with 35,759 preterm infants, were included in the analysis of necrotizing enter colitis (NEC)/Intestinal perforation (IP) rates. There was a significant increase in NEC/IP rates in prophylactic indomethacin group when compared to the placebo/no treatment group (OR= 1.36; $95 \% \mathrm{Cl}=1.24-1.49 ; \mathrm{P}-$ value< 0.001$)$. Moreover, there was no significant heterogeneity among the included studies $\left(I^{2}=44 \%\right.$; P-value $\left.=0.088\right)($ Figure 6$)$.

In the same context, death rates were compared in 47,265 patients of 13 included studies. There were no significant differences in death rates of prophylactic indomethacin group when compared to the placebo/no treatment group ( $\mathrm{OR}=1.06 ; 95 \% \mathrm{Cl}=0.94-1.19 ; \mathrm{P}$-value=0.340). However, there was significant heterogeneity among the included studies $\left(\mathrm{I}^{2}=69 \%\right.$; P-value $\left.<0.001\right)$. There was no significant risk of bias when tested using Egger's regression test $(\mathrm{P}$-value= 0.428) (Figure 7).

\section{Hospitalization outcomes}

Two studies of 340 patients were included in the analyses of hospitalization days and days spent of ventilation. On comparing these outcomes among the prophylactic indomethacin and placebo/no treatment groups, there was no statistically significant difference for hospitalization days $(\mathrm{MD}=3.67 ; 95 \% \mathrm{Cl}=$ -11.03-18.37; P-value = 0.625) and days spent of ventilation $(\mathrm{MD}=-1.00 ; 95 \% \mathrm{Cl}=-6.71-4.71 ; \mathrm{P}$-value $=0.732)$. There was a significant heterogeneity in the analysis of hospitalization days $\left(I^{2}=56 \%\right.$; P-value= 0.132$)$, while it was not present in the analysis of days spent of ventilation $\left(I^{2}=0 \%\right.$; $P$-value= 1.000$)($ Figure 8).

\section{Prevalence of different outcomes in indomethacin group}

For studies with a single prophylactic indomethacin group (no placebo/no treatment group), they were pooled with all other studies (two-armed) with similar outcomes to get the overall prevalence. The highest prevalence observed in pre-term infants with prophylactic indomethacin was the intubation in delivery room/first day $(74 \% ; 95 \% \mathrm{Cl}=52.9-100.0)$, followed by BPD $(33.2 \% ; 95 \% \mathrm{Cl}=25.6-43.1)$, PDA $(32.2 \% ; 95 \% \mathrm{Cl}=27.3-38.0)$ and IVH (26.1\%; 95\% Cl= 19.1-35.7), respectively (Figure 9). All prevalence analyses showed a significant heterogeneity $\left(\mathrm{I}^{2}>50 \%\right.$; P-value< 0.001$)$; however, there was no significant risk of bias in all analyses (Egger's P-value >0.10). Table 2 details the prevalence of different outcomes in the prophylactic indomethacin group.

\section{Discussion}

In this study, we have included 22 studies from the systematic and manual search to be analyzed to study indomethacin as a prophylactic measurement in pre-term infants from many aspects including the cardiopulmonary, neurodevelopmental delays, necrotizing enterocolitis/Intestinal perforation and death, days of hospitalization and the time spent on mechanical ventilation together with the prevalence of these outcomes from eligible study designs. The pooled results of our analysis showed that intubation on the first day at the delivery room was the most prevalent outcome, while pulmonary hemorrhage was the least. In general, these rates are like previously published reports. Laptook et al. (43) reported a prevalence rate of $29.2 \%$ for neurodevelopmental delays VLBW infants. PDA was prevalent in $65.57 \%$ in neonates at birth and $41 \%$ of the patient who received indomethacin did not have favorable outcomes in Koch et al. study (44). The quality of the included studies was good in general which is suggestive of valid data included in the analysis. However, analyzed data showed various heterogeneity in some outcomes which is probably due to the difference in study designs, the different dosages of indomethacin injection, and outcome definition between studies.

As for the cardiopulmonary outcomes, our analysis showed that prophylactic indomethacin administration in infants significantly lowers the rates of PDA formation (P-value< 0.001). Although, significant heterogeneity was estimated $\left(I^{2}=72 \%\right.$; $P$-value $\left.<0.001\right)$ due to the different study designs that were included in the analysis, our results were similar to previously published studies $(45,46)$. On the other hand, the effect of indomethacin on BPD and pulmonary hemorrhage rates was statistically non-significant ( $\mathrm{P}$-value $=106$ and 0.132 , respectively). This is consistent with previously published meta-analysis studies of RCTs which found significance in terms of lowering PDA rates, but no difference in terms of BPD (45). Jensen et al. (46) in their analysis of observational data found that prophylactic indomethacin did not increase or decrease the risk of developing BPD. Moreover, the authors compared these results with another analysis of RCTs, however, the analysis indicated the same information that prophylactic indomethacin had no beneficial effects of BPD.

In terms of neurodevelopmental outcomes, our analysis showed that indomethacin prophylaxis did not significantly reduce the risk of IVH and $\mathrm{CP} /$ neurodevelopmental outcomes in preterm infants when compared to the placebo group ( $P$-value $=0.460$ and 0.997 , respectively). Our results are consistent with the results of Cooke et al. (47) which found no significance on the effect of prophylactic indomethacin on IVH and other neurodevelopmental abnormalities as retinopathy of prematurity. On the other hand, Fowlie et al. found a significant reduction in IVH incidence in infants that were prophylactically injected with indomethacin. However, significant heterogeneity in this study was estimated due to the inconsistency of treatment efficacy among their included studies (45). None of the studies, however, measured the long-term outcomes, they have only focused on the short ones. Schmidt et al. (15) in their big trial on 18-month infants reported statistical insignificance on long term neurodevelopmental outcomes although IVH grade 3 and 4 were significantly reduced. Therefore, concerns should be made to assess the overall quality of the effect of indomethacin on the long-term neurodevelopmental outcomes and the rate of adverse events incidence due to the vasoconstrictive nature of the drug which may alter the cerebral blood flow.

Other adverse events of prophylactic indomethacin application include increase incidence rates of necrotizing enter colitis (NEC)/Intestinal perforation (IP). In our study, a significant increase in the rate of these outcomes was estimated (P-value< 0.001$)$. Our study results are inconsistent with the results of other previously published systematic reviews which found no significance on the effect of indomethacin on increasing the incidence of NEC (14, 45, 47). Additionally, other events were discussed by these studies as the effect of indomethacin on renal function. Fowlie et al. (14) found significance in the increased rate of oliguria but not creatinine levels. 
Furthermore, we found no significance between the use of prophylactic indomethacin on infants in reducing the time of hospital stay and time spent on mechanical ventilation. Fowlie et al. (14) result favored the control groups in terms of time spent in the hospital with no significance $(P=0.087)$, however, the opposite was reported with the time spent on ventilation with reported statistical significance $(P=0.33)$. Besides, the data of 13 included studies showed no significance in reducing the rates of mortality in infants that received prophylactic indomethacin $(P=0.34)$. Despite the heterogeneity in our analysis, the results are consistent with these shown by Fowlie et al. $(14,45)$. On the other hand, Jensen et al. (46) subgroup analysis showed a low rate of mortality in the infants that received prophylactic indomethacin with no intrauterine growth restriction and with no requirement for subsequent PDA treatment. However, the authors included observational data only.

Limitations to our study include the significant heterogeneity in the analysis of some outcomes due to the different study designs that were included in this study. However, we estimated the risk of bias in most cases when significant heterogeneity was estimated, and no significant risk was found in these events.

\section{Conclusion}

Prophylactic indomethacin in VLBW infants has proven efficient in preventing short-term events as PDA. Our analysis, however, showed no significance on IVH despite the many investigations that were published before which showed that indomethacin can reduce the incidence of IVH and other neurodevelopmental abnormalities. Consequently, and based on the findings that higher rates of NEC/IP and the neutral effect on infant mortality, the use of prophylactic indomethacin should be generally discouraged until a proper assessment of the case has been provided.

\section{Abbreviations}

Patent ductus arteriosus (PDA); Necrotizing enter colitis (NEC); Intestinal perforation (IP); Intraventricular hemorrhage (IVH); Bronchopulmonary dysplasia (BPD); Very low birth weight (VLBW).

\section{Declarations}

This study by analysis of existing publicaions and not involve with patient so consent was not indicated.

\section{Ethical approval}

Ethical approval was obtained from the Institutional Review Board in King Fahad Medical City, Riyadh, Saudi Arabia before any study started.

\section{Availability of the data and Materials}

Data is available upon request.

\section{Competing interest}

The authors have no conflicts of interest to declare

\section{Funding}

This research did not receive any specific grant from funding agencies in the public, commercial, or not-for-profit sectors.

\section{Author Contributor}

N/A

\section{Acknowledgments}

The author would like to thanks the Research Centre, King Fahad Medical City, Riyadh, Saudi Arabia, for providing support in preparing this manuscript.

\section{References}

1. Schmidt B, Asztalos EV, Roberts RS, Robertson CM, Sauve RS, Whitfield MF. Impact of bronchopulmonary dysplasia, brain injury, and severe retinopathy on the outcome of extremely low-birth-weight infants at 18 months: results from the trial of indomethacin prophylaxis in preterms. Jama. 2003;289(9):1124-9.

2. Laptook AR, O'Shea TM, Shankaran S, Bhaskar B. Adverse neurodevelopmental outcomes among extremely low birth weight infants with a normal head ultrasound: prevalence and antecedents. Pediatrics. 2005;115(3):673-80.

3. Vohr B, Garcia Coll C, Flanagan P, Oh W. Effects of intraventricular hemorrhage and socioeconomic status on perceptual, cognitive, and neurologic status of low birth weight infants at 5 years of age. The Journal of pediatrics. 1992;121(2):280-5.

4. Piecuch RE, Leonard CH, Cooper BA, Kilpatrick SJ, Schlueter MA, Sola A. Outcome of infants born at 24-26 weeks' gestation: II. Neurodevelopmental outcome. Obstetrics and gynecology. 1997;90(5):809-14.

5. Shaver DC, Bada HS, Korones SB, Anderson GD, Wong SP, Arheart KL. Early and late intraventricular hemorrhage: the role of obstetric factors. Obstetrics and gynecology. 1992;80(5):831-7. 
6. Ment LR, Duncan CC, Ehrenkranz RA, Lange RC, Taylor KJ, Kleinman CS, et al. Intraventricular hemorrhage in the preterm neonate: timing and cerebral blood flow changes. The Journal of pediatrics. 1984;104(3):419-25.

7. Vohr B, Allan WC, Scott DT, Katz KH, Schneider KC, Makuch RW, et al. Early-onset intraventricular hemorrhage in preterm neonates: incidence of neurodevelopmental handicap. Seminars in perinatology. 1999;23(3):212-7.

8. Dolfin T, Skidmore MB, Fong KW, Hoskins EM, Shennan AT. Incidence, severity, and timing of subependymal and intraventricular hemorrhages in preterm infants born in a perinatal unit as detected by serial real-time ultrasound. Pediatrics. 1983;71(4):541-6.

9. Philip AG, Allan WC, Tito AM, Wheeler LR. Intraventricular hemorrhage in preterm infants: declining incidence in the 1980s. Pediatrics. $1989 ; 84(5): 797-801$.

10. Marba ST, Caldas JP, Vinagre LE, Pessoto MA. Incidence of periventricular/intraventricular hemorrhage in very low birth weight infants: a 15-year cohort study. Jornal de pediatria. 2011;87(6):505-11.

11. Jain NJ, Kruse LK, Demissie K, Khandelwal M. Impact of mode of delivery on neonatal complications: trends between 1997 and 2005 . The journal of maternal-fetal \& neonatal medicine : the official journal of the European Association of Perinatal Medicine, the Federation of Asia and Oceania Perinatal Societies, the International Society of Perinatal Obstet. 2009;22(6):491-500.

12. McCrea HJ, Ment LR. The diagnosis, management, and postnatal prevention of intraventricular hemorrhage in the preterm neonate. Clinics in perinatology. 2008;35(4):777-vii.

13. Ballabh P. Intraventricular hemorrhage in premature infants: mechanism of disease. Pediatric research. 2010;67(1):1-8.

14. Fowlie PW, Davis PG, McGuire W. Prophylactic intravenous indomethacin for preventing mortality and morbidity in preterm infants. The Cochrane database of systematic reviews. 2010;2010(7):Cd000174.

15. Schmidt B, Davis P, Moddemann D, Ohlsson A, Roberts RS, Saigal S, et al. Long-term effects of indomethacin prophylaxis in extremely-low-birth-weight infants. The New England journal of medicine. 2001;344(26):1966-72.

16. Ment LR, Oh W, Ehrenkranz RA, Philip AG, Vohr B, Allan W, et al. Low-dose indomethacin and prevention of intraventricular hemorrhage: a multicenter randomized trial. Pediatrics. 1994;93(4):543-50.

17. Mirza H, Oh W, Laptook A, Vohr B, Tucker R, Stonestreet BS. Indomethacin prophylaxis to prevent intraventricular hemorrhage: association between incidence and timing of drug administration. The Journal of pediatrics. 2013;163(3):706-10.e1.

18. Alfaleh K, Smyth JA, Roberts RS, Solimano A, Asztalos EV, Schmidt B. Prevention and 18-Month Outcomes of Serious Pulmonary Hemorrhage in Extremely Low Birth Weight Infants: Results From the Trial of Indomethacin Prophylaxis in Preterms. Pediatrics. 2008;121(2):e233.

19. Coyle MG, Oh W, Petersson KH, Stonestreet BS. Effects of indomethacin on brain blood flow, cerebral metabolism, and sagittal sinus prostanoids after hypoxia. The American journal of physiology. 1995;269(4 Pt 2):H1450-9.

20. Coyle MG, Oh W, Stonestreet BS. Effects of indomethacin on brain blood flow and cerebral metabolism in hypoxic newborn piglets. The American journal of physiology. 1993;264(1 Pt 2):H141-9.

21. Leffler CW, Mirro R, Shibata M, Parfenova H, Armstead WM, Zuckerman S. Effects of indomethacin on cerebral vasodilator responses to arachidonic acid and hypercapnia in newborn pigs. Pediatric research. 1993;33(6):609-14.

22. McCalden TA, Nath RG, Thiele K. The role of prostacyclin in the hypercapnic and hypoxic cerebrovascular dilations. Life sciences. 1984;34(19):1801-7.

23. Zuckerman SL, Mirro R, Armstead WM, Shibata M, Leffler CW. Indomethacin reduces ischemia-induced alteration of blood-brain barrier transport in piglets. The American journal of physiology. 1994;266(6 Pt 2):H2198-203.

24. Ment LR, Stewart WB, Ardito TA, Huang E, Madri JA. Indomethacin promotes germinal matrix microvessel maturation in the newborn beagle pup. Stroke. 1992;23(8):1132-7.

25. Ando Y, Takashima S, Takeshita K. Cerebral blood flow velocity in preterm neonates. Brain and Development. 1985;7(4):385-91.

26. Ment LR, Oh W, Ehrenkranz RA, Philip AG, Schneider K, Katz KH, et al. Risk period for intraventricular hemorrhage of the preterm neonate is independent of gestational age. Seminars in perinatology. 1993;17(5):338-41.

27. Bandstra ES, Montalvo BM, Goldberg RN, Pacheco I, Ferrer PL, Flynn J, et al. Prophylactic indomethacin for prevention of intraventricular hemorrhage in premature infants. Pediatrics. 1988;82(4):533-42.

28. Bada HS, Green RS, Pourcyrous M, Leffler CW, Korones SB, Magill HL, et al. Indomethacin reduces the risks of severe intraventricular hemorrhage. The Journal of pediatrics. 1989;115(4):631-7.

29. Ment LR, Oh W, Ehrenkranz RA, Phillip AG, Vohr B, Allan W, et al. Low-dose indomethacin therapy and extension of intraventricular hemorrhage: a multicenter randomized trial. The Journal of pediatrics. 1994;124(6):951-5.

30. Edwards AD, Wyatt JS, Richardson C, Potter A, Cope M, Delpy DT, et al. Effects of indomethacin on cerebral haemodynamics in very preterm infants. Lancet (London, England). 1990;335(8704):1491-5.

31. Saliba E, Chantepie A, Autret E, Gold F, Pourcelot L, Laugier J. Effects of indomethacin on cerebral hemodynamics at rest and during endotracheal suctioning in preterm neonates. Acta paediatrica Scandinavica. 1991;80(6-7):611-5.

32. Liberati A, Altman DG, Tetzlaff J, Mulrow C, Gotzsche PC, loannidis JPA, et al. The PRISMA Statement for Reporting Systematic Reviews and MetaAnalyses of Studies That Evaluate Health Care Interventions: Explanation and Elaboration. Plos Medicine. 2009;6(7):28.

33. Vassar M, Atakpo P, Kash MJ. Manual search approaches used by systematic reviewers in dermatology. Journal of the Medical Library Association: JMLA. 2016;104(4):302.

34. Higgins JPT, Altman DG, Gøtzsche PC, Jüni P, Moher D, Oxman AD, et al. The Cochrane Collaboration's tool for assessing risk of bias in randomised trials. BMJ (Clinical research ed). 2011;343. 
35. Health Nlo. Quality assessment tool for observational cohort and cross-sectional studies. National Heart, Lung, and Blood Institute Avaliable from: www nhlbi nih gov/health-pro/guidelines/indevelop/cardiovascular-risk-reduction/tools/cohort[Accessed November 5, 2015$] .2014$.

36. Team RC. R: A Language and Environment for Statistical Computing. Vienna, Austria: R Foundation for Statistical Computing; 2017.

37. Schwarzer G. meta: General Package for Meta-Analysis. 4.9-7 ed2019.

38. Higgins JP, Green S. Cochrane Handbook for Systematic Reviews of Interventions (Identifying and measuring heterogeneity)2011 March 2011.

39. Egger M, Smith GD, Schneider M, Minder C. Bias in meta-analysis detected by a simple, graphical test. BMJ (Clinical research ed). 1997;315(7109):629-34.

40. Peters JL, Sutton AJ, Jones DR, Abrams KR, Rushton L. Comparison of two methods to detect publication bias in meta-analysis. Jama. 2006;295(6):67680.

41. Begg CB, Mazumdar M. Operating characteristics of a rank correlation test for publication bias. Biometrics. 1994:1088-101.

42. Duval S, Tweedie R. Trim and fill: a simple funnel-plot-based method of testing and adjusting for publication bias in meta-analysis. Biometrics. 2000;56(2):455-63.

43. Laptook AR, Shea TM, Shankaran S, Bhaskar B. Adverse Neurodevelopmental Outcomes Among Extremely Low Birth Weight Infants With a Normal Head Ultrasound: Prevalence and Antecedents. Pediatrics. 2005;115(3):673.

44. Koch J, Hensley G, Roy L, Brown S, Ramaciotti C, Rosenfeld CR. Prevalence of Spontaneous Closure of the Ductus Arteriosus in Neonates at a Birth Weight of 1000 Grams or Less. Pediatrics. 2006;117(4):1113.

45. Fowlie PW, Davis PG. Prophylactic indomethacin for preterm infants: a systematic review and meta-analysis. Arch Dis Child Fetal Neonatal Ed. 2003;88(6):F464-F6.

46. Jensen EA, Foglia EE, Schmidt B. Association between prophylactic indomethacin and death or bronchopulmonary dysplasia: A systematic review and meta-analysis of observational studies. Seminars in perinatology. 2018;42(4):228-34.

47. Cooke L, Steer P, Woodgate P. Indomethacin for asymptomatic patent ductus arteriosus in preterm infants. The Cochrane database of systematic reviews. 2003(2):Cd003745.

\section{Tables}

Table 1. Characteristics of the included studies 


\begin{tabular}{|c|c|c|c|c|c|c|c|c|c|c|c|c|c|c|c|c|}
\hline \multirow{3}{*}{$\begin{array}{l}\text { Author } \\
\text { Year }\end{array}$} & \multirow[t]{3}{*}{ Design } & \multirow{3}{*}{$\begin{array}{l}\text { Sample } \\
\text { Size }\end{array}$} & \multicolumn{6}{|c|}{ Gestational Age } & \multicolumn{6}{|c|}{ Birth Weight } & \multirow{2}{*}{\multicolumn{2}{|c|}{$\begin{array}{l}\text { Male } \\
\text { Treatment } \\
\text { Group }\end{array}$}} \\
\hline & & & \multicolumn{3}{|c|}{ Treatment Group } & \multicolumn{3}{|c|}{ Control Group } & \multicolumn{3}{|c|}{ Treatment Group } & \multicolumn{3}{|c|}{ Control Group } & & \\
\hline & & & Total & Mean & SD & Total & Mean & SD & Total & Mean & SD & Total & Mean & SD & Event & Total \\
\hline $\begin{array}{l}\text { Alfaleh et } \\
\text { al. } 2008\end{array}$ & $\mathrm{RCT}$ & 1202 & 1202 & 25.91 & 1.87 & - & - & - & - & - & - & - & - & - & 615 & 1202 \\
\hline
\end{tabular}

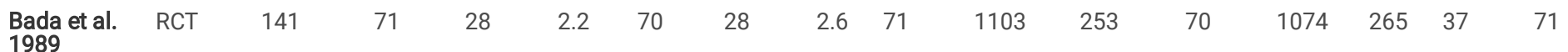

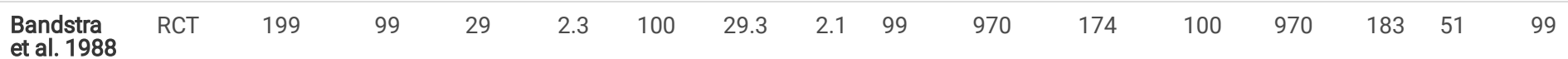

$\begin{array}{lllllllllllllllllllll}\text { Bhat et al. } & \text { Cohort } & 1154 & 912 & 25.1 & 1.94 & - & - & - & 912 & 687.6 & 179.39 & - & - & - & 442 & 912\end{array}$
2019

Clyman et $\quad$ RCT 1202 al. 2007 


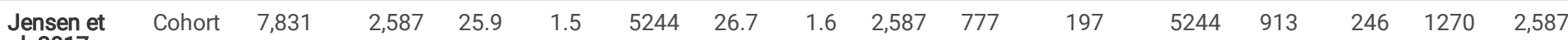

al. 2017

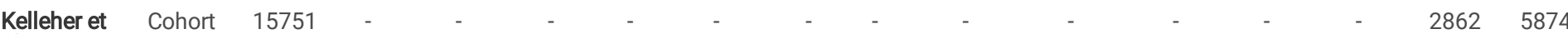

al. 2014

Laughon

Cohort 34602

et al. 2007

3293

6189

Liebowitz Cohort 313

215

26.1

1.198

26.1

$1.1 \quad 215$

833

203

98

826

$205 \quad 114$

215

\section{Liebowitz}

Cohort 397

247

26.1

$1.2 \quad 150 \quad 26$

$1.2 \quad 247$

813

197

150

802

$200 \quad 117$

247

et al. 2017

Maruyama RCT

et al. 2012

Page $10 / 20$ 
$\begin{array}{llllllllllllllll}\text { Mirza et al. } & \text { Cohort } & 868 & 868 & 26.36 & 1.97 & - & - & - & 868 & 864.82 & 210.84 & - & - & - & 431\end{array}$ 2013

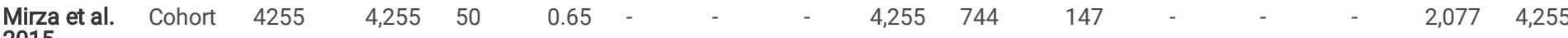

Nelin et al.

2017 


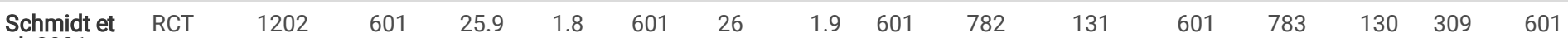
al. 2001

Schmidt et

Cohort 910

910

26.2

1.8

$910 \quad 793$

127

910

Schmidt et

al. 2006

Cohort 999

.

Cohort

Schmidt et Cohort 1202

al. 2011 
SD: standard deviation; RCT: randomized controlled trial

Table 2. Prevalence of different outcomes in the prophylactic indomethacin group

\begin{tabular}{|c|c|c|c|c|c|c|c|c|c|}
\hline \multirow[t]{2}{*}{ Outcome } & \multirow[t]{2}{*}{ Prevalence } & \multirow[t]{2}{*}{$\mathrm{LCl}$} & \multirow[t]{2}{*}{$\mathrm{UCl}$} & \multirow[t]{2}{*}{$\mathbf{N}$} & \multirow[t]{2}{*}{ Event } & \multirow[t]{2}{*}{ Total } & \multicolumn{3}{|c|}{ Heterogeneity measures } \\
\hline & & & & & & & $p^{2}$ & $\tau^{2}$ & P-value \\
\hline Intubated in delivery room/First day & 74.9 & 52.9 & 100.0 & 3 & 369 & 445 & $97 \%$ & 0.09 & $<0.001$ \\
\hline Bronchopulmonary dysplasia & 33.2 & 25.6 & 43.1 & 6 & 1772 & 4801 & $97 \%$ & 0.10 & $<0.001$ \\
\hline Patent Ductus Arteriosus & 32.2 & 27.3 & 38.0 & 13 & 4800 & 14003 & $97 \%$ & 0.08 & $<0.001$ \\
\hline Intraventricular Hemornhage & 26.1 & 19.1 & 35.7 & 12 & 3526 & 14898 & $99 \%$ & 0.28 & $<0.001$ \\
\hline CP/Neurodevelopmental delay & 19.1 & 12.9 & 28.2 & 6 & 1889 & 9031 & $99 \%$ & 0.23 & $<0.001$ \\
\hline Death & 17.8 & 12.1 & 26.1 & 15 & 4722 & 23794 & $100 \%$ & 0.53 & $<0.001$ \\
\hline NEC/Intestinal perforation & 10.0 & 6.9 & 14.4 & 10 & 1460 & 15029 & $97 \%$ & 0.29 & $<0.001$ \\
\hline Pulmonary Hemorrhage & 8.3 & 5.4 & 12.8 & 5 & 212 & 2284 & $88 \%$ & 0.19 & $<0.001$ \\
\hline
\end{tabular}

LCI: 95\% low confidence interval; N: number of the included studies; UCI: 95\% upper confidence interval; NEC: necrotizing enterocolitis

\section{Figures}




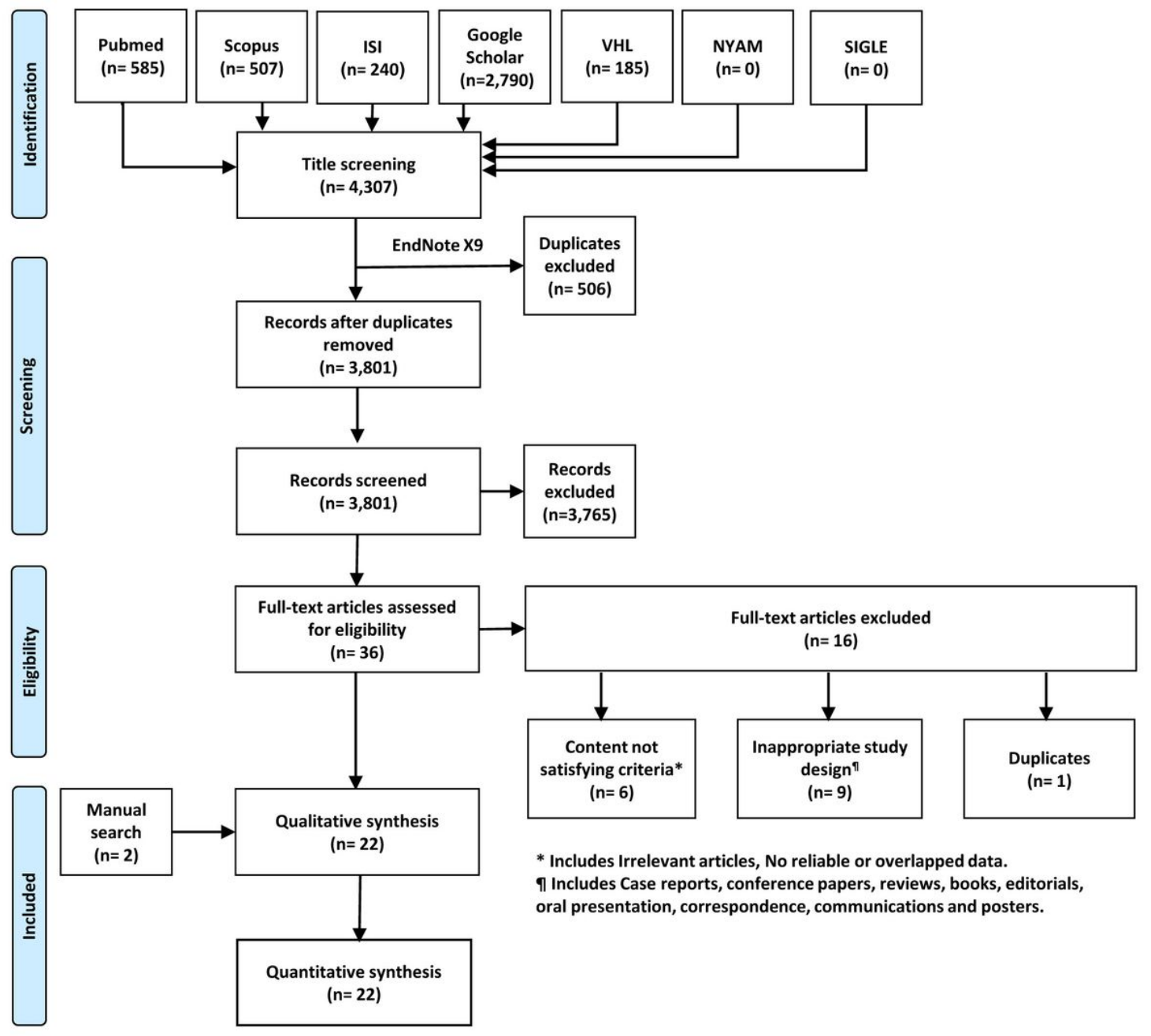

Figure 1

PRISMA flowchart of the search and screening process. 
Bias arising from the randomization process Bias due to deviations from intended interventions

Bias due to missing outcome data Bias in measurement of the outcome Bias in selection of the reported result Overall risk of bias
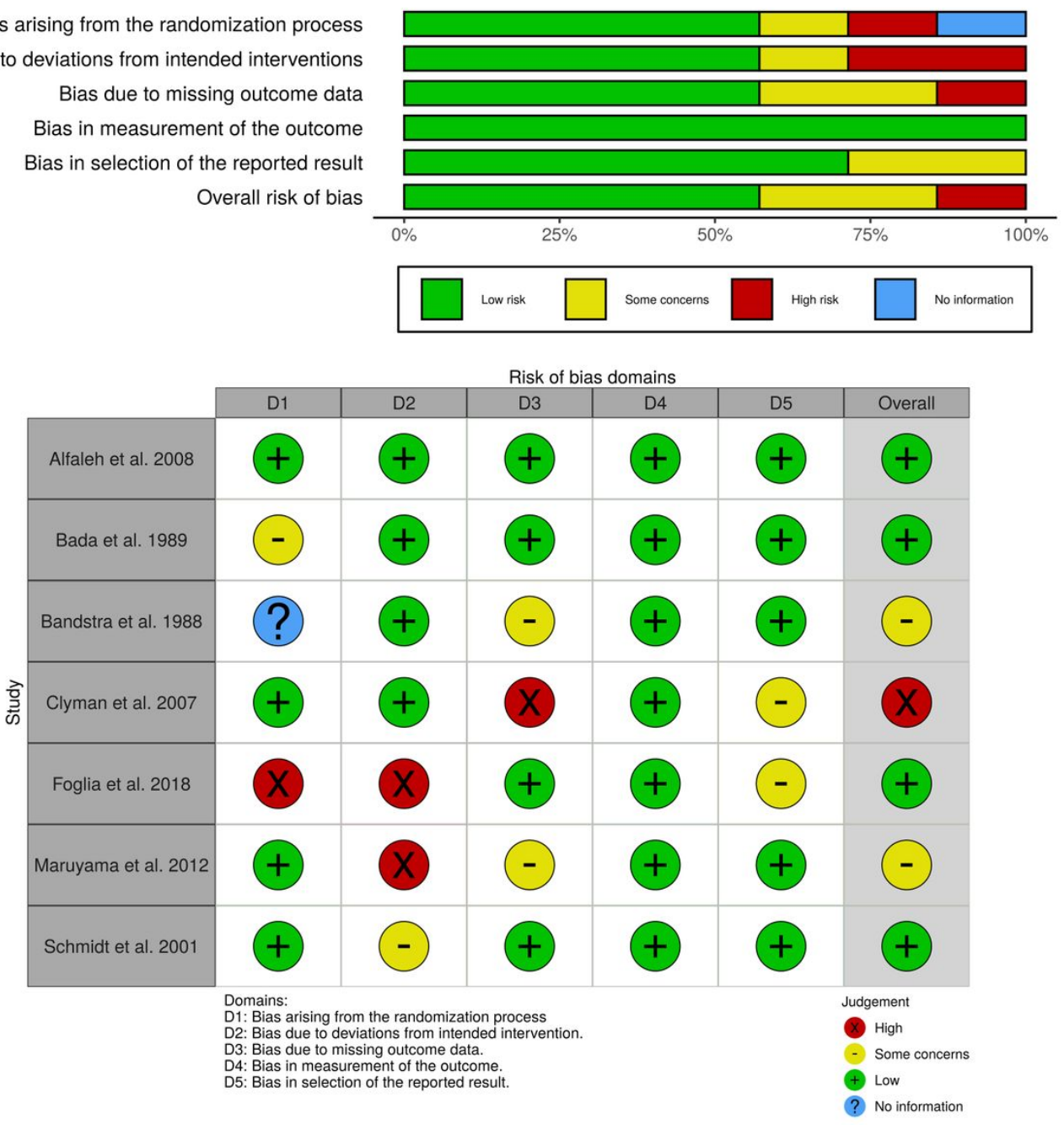

\section{Figure 2}

Quality of the included randomized controlled trials. A: Risk of bias graph: review authors' judgements about each risk of bias item presented as percentages across all included studies; B: Risk of bias summary: review authors' judgements about each risk of bias item for each included study. 
Bias due to confounding Bias due to selection of participants Bias in classification of interventions Bias due to deviations from intended interventions Bias due to missing data Bias in measurement of outcomes Bias in selection of the reported result Overall risk of bias
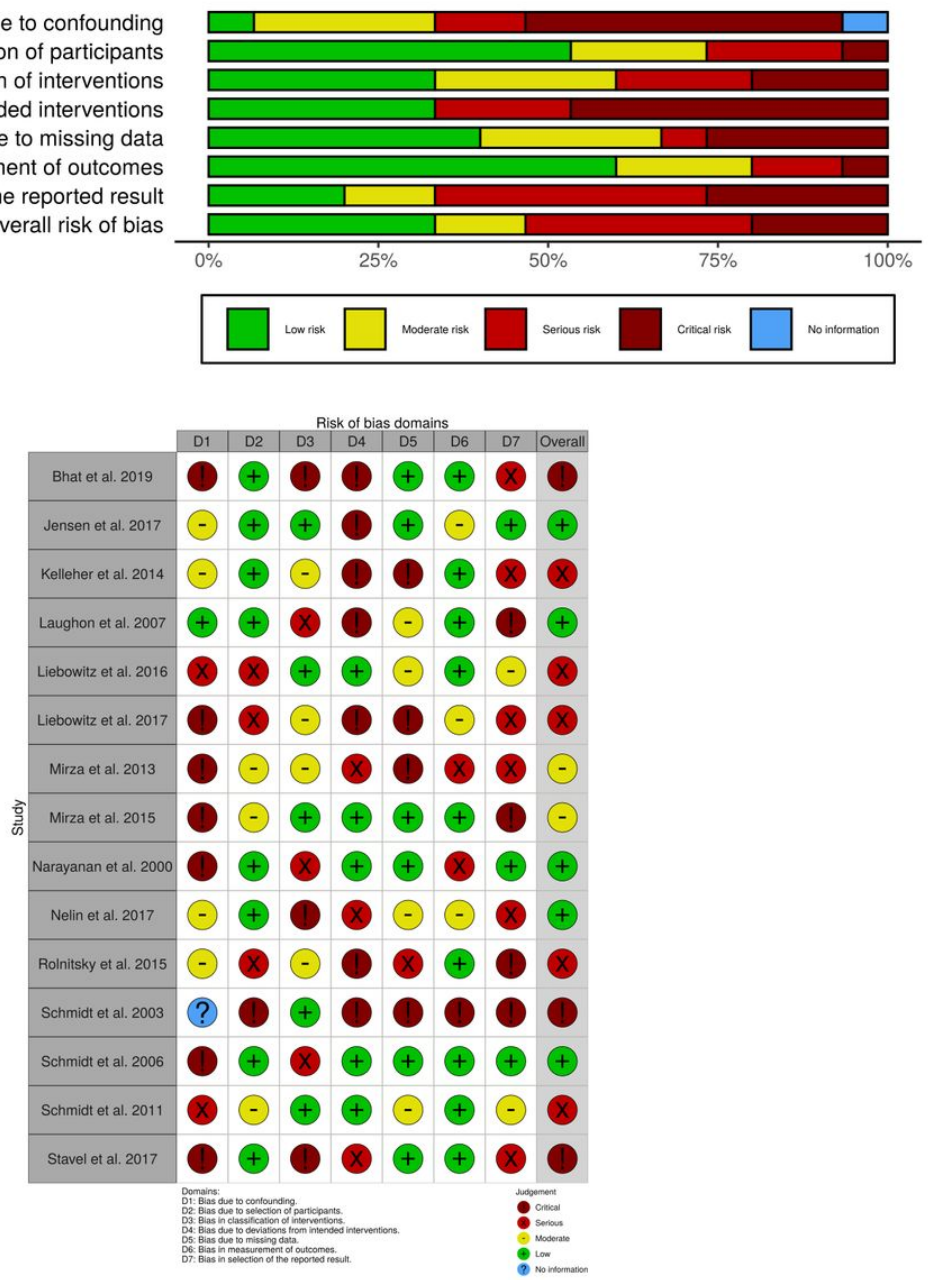

Figure 3

Quality of the included non-randomized controlled trials. A: Risk of bias graph: review authors' judgements about each risk of bias item presented as percentages across all included studies; B: Risk of bias summary: review authors' judgements about each risk of bias item for each included study. 


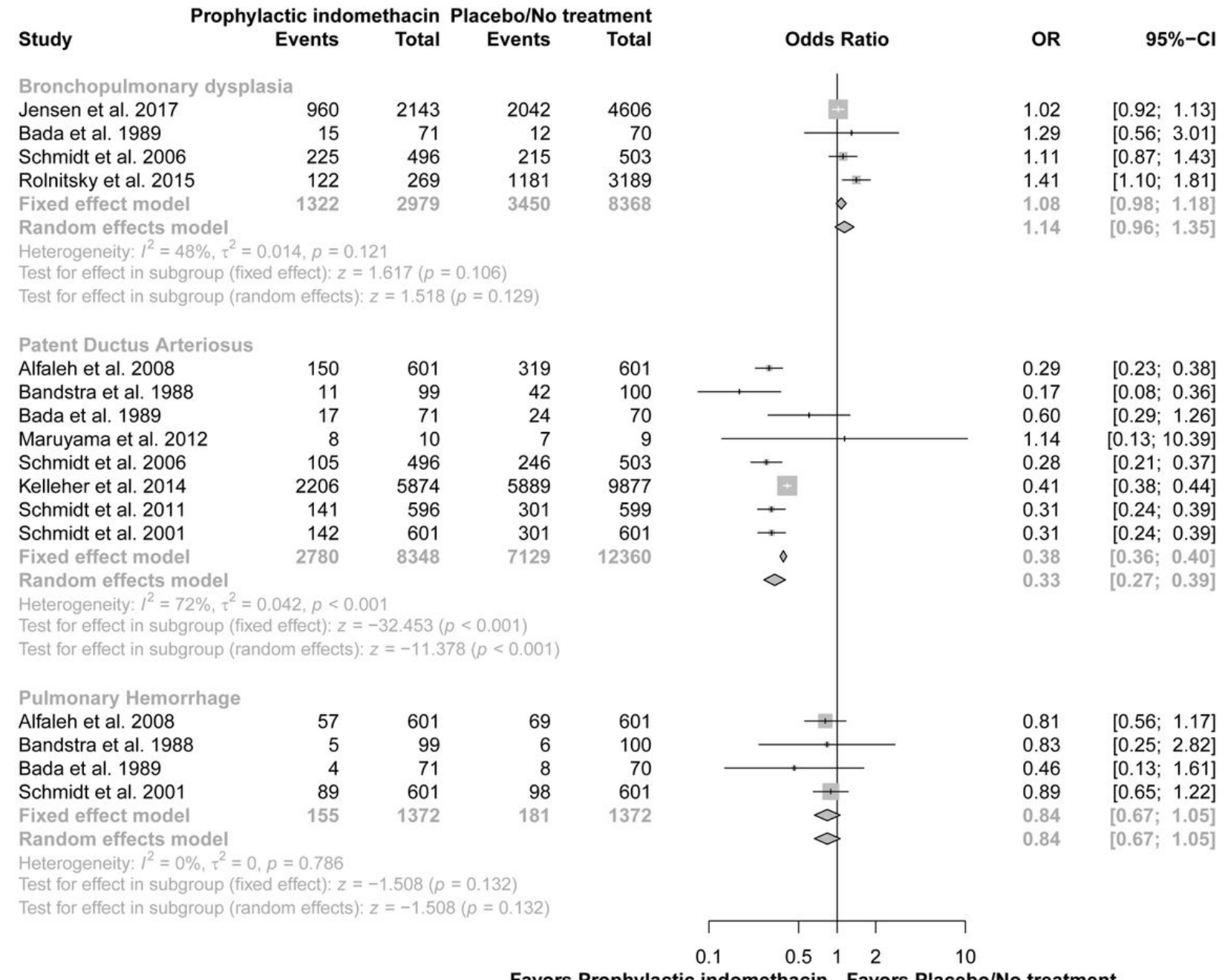

Favors Prophylactic indomethacin Favors Placebo/No treatment

Figure 4

Forest plot for cardiopulmonary outcomes. 
Intraventricular Hemorrhage

Events Total Events Total

Odds Ratio

OR

$95 \%-\mathrm{Cl}$

Bandstra et al. 1988

Bada et al. 1989

Maruyama et al. 2012

Foglia et al. 2018

Rolnitsky et al. 2015

Laughon et al. 2007

Schmidt et al. 2011

Nelin et al. 2017

Schmidt et al. 2001

Fixed effect model

Random effects model

Heterogeneity: $I^{2}=84 \%, \tau^{2}=0.112, p<0.001$

Test for effect in subgroup (fixed effect): $z=1.533(p=0.125)$

Test for effect in subgroup (random effects): $z=-0.739(p=0.460)$

CP/Neurodevelopmental delay

$\begin{array}{lrrrr}\text { Clyman et al. 2007 } & 234 & 601 & 228 & 601 \\ \text { Foglia et al. 2018 } & 270 & 716 & 259 & 565 \\ \text { Kelleher et al. 2014 } & 1179 & 5874 & 1741 & 9877 \\ \text { Schmidt et al. 2011 } & 56 & 463 & 55 & 475 \\ \text { Schmidt et al. 2001 } & 58 & 467 & 55 & 477 \\ \text { Fixed effect model } & 1797 & 8121 & 2338 & 11995\end{array}$

Random effects model

Heterogeneity: $I^{2}=76 \%, \tau^{2}=0.039, p=0.002$

Test for effect in subgroup (fixed effect): $z=2.590(p=0.010)$

Test for effect in subgroup (random effects): $z=-0.003(p=0.997)$

$$
\begin{array}{r}
100 \\
70 \\
9 \\
563 \\
3189 \\
3886 \\
565 \\
137 \\
567 \\
9086
\end{array}
$$

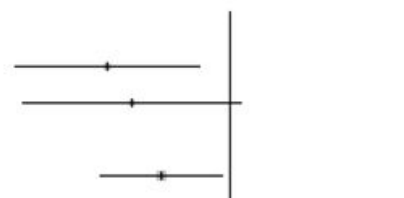

0.47

$[0.28 ; 1.07]$

0.66

1.88

$[0.45 ; 0.95]$

1.14

$[1.44 ; 2.45]$

0.66

$[1.01 ; 1.29]$

1.10

$[0.45 ; 0.96]$

1.01

$[0.80 ; 1.28]$

1.07

$[0.98 ; 1.17]$

$0.90 \quad[0.69 ; 1.18]$

1.04

$[0.83 ; 1.32]$

0.72

$[0.57 ; 0.89]$

1.17

$[1.08 ; 1.27]$

1.05

$[0.71 ; 1.56]$

1.09

$[0.73 ; 1.61]$

1.10

$[1.02 ; 1.18]$

1.00

$[0.81 ; 1.23]$

Favors Prophylactic indomethacin Favors Placebo/No treatment

Figure 5

Forest plot for neurodevelopmental outcomes.

\begin{tabular}{|c|c|c|c|c|}
\hline \multirow[b]{2}{*}{ Study } & \multicolumn{2}{|c|}{ rophylactic indomethacin } & \multicolumn{2}{|c|}{ lacebo/No treatment } \\
\hline & Events & Total & Events & Total \\
\hline Bandstra et al. 1988 & 6 & 99 & 3 & 100 \\
\hline Bada et al. 1989 & 6 & 71 & 7 & 70 \\
\hline Maruyama et al. 2012 & 0 & 10 & 0 & 9 \\
\hline Kelleher et al. 2014 & 269 & 5874 & 383 & 9877 \\
\hline Rolnitsky et al. 2015 & 31 & 269 & 290 & 3189 \\
\hline Laughon et al. 2007 & 788 & 6189 & 337 & 3886 \\
\hline Nelin et al. 2017 & 83 & 506 & 23 & 140 \\
\hline Schmidt et al. 2001 & 100 & 601 & 90 & 601 \\
\hline Stavel et al. 2016 & 26 & 498 & 103 & 3770 \\
\hline Fixed effect model & 1309 & 14117 & 1236 & 21642 \\
\hline
\end{tabular}

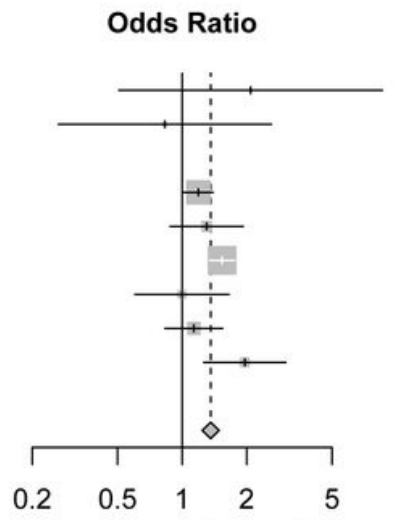

OR

$95 \%-\mathrm{Cl}$

Weight

Heterogeneity: $I^{2}=44 \%, \tau^{2}=0.017, p=0.088$

Test for overall effect: $z=6.622(p<0.001)$

$\begin{array}{llr}2.09 & {[0.51 ; 8.59]} & 0.4 \% \\ 0.83 & {[0.26 ; 2.61]} & 0.6 \% \\ & & 0.0 \% \\ 1.19 & {[1.01 ; 1.40]} & 32.3 \% \\ 1.30 & {[0.88 ; 1.93]} & 5.3 \% \\ 1.54 & {[1.34 ; 1.76]} & 45.4 \% \\ 1.00 & {[0.60 ; 1.65]} & 3.2 \% \\ 1.13 & {[0.83 ; 1.55]} & 8.5 \% \\ 1.96 & {[1.26 ; 3.05]} & 4.2 \% \\ & & \\ 1.36 & {[1.24 ; 1.49]} & 100.0 \%\end{array}$

Favors Prophylactic indomethacin Favors Placebo/No treatment

Figure 6

Forest plot for necrotizing enterocolitis/intestinal perforation. 


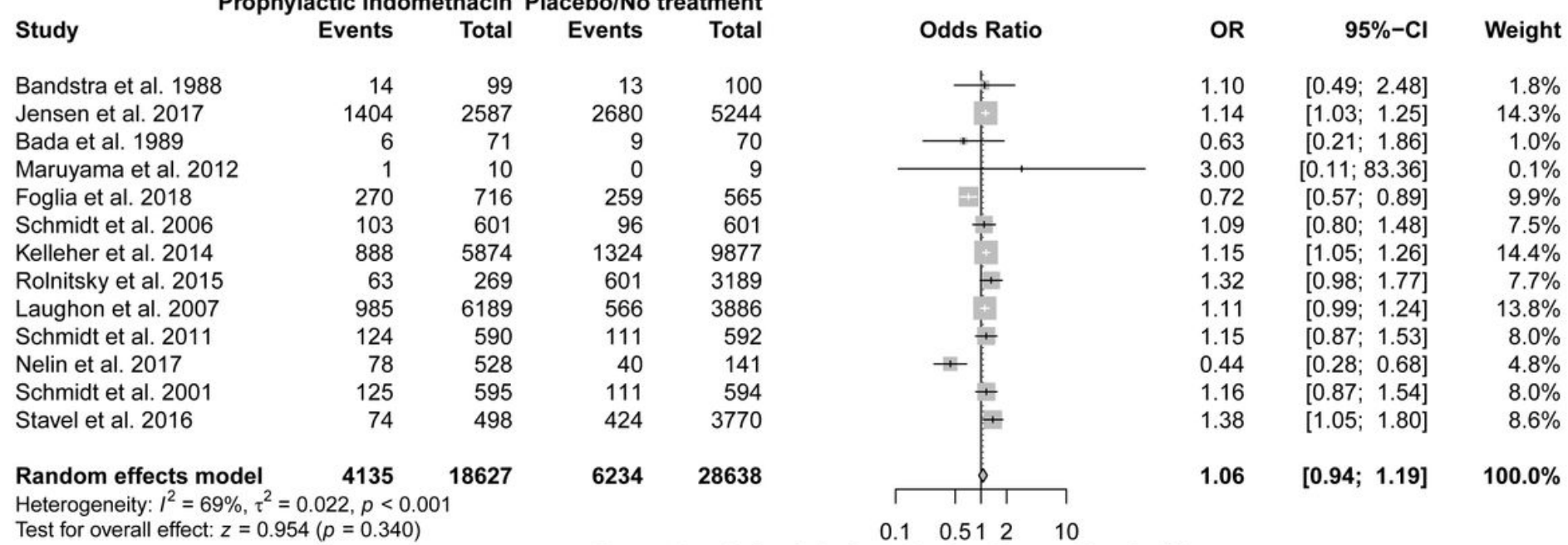

Favors Prophylactic indomethacin Favors Placebo/No treatment

Figure 7

Forest plot for death rates.

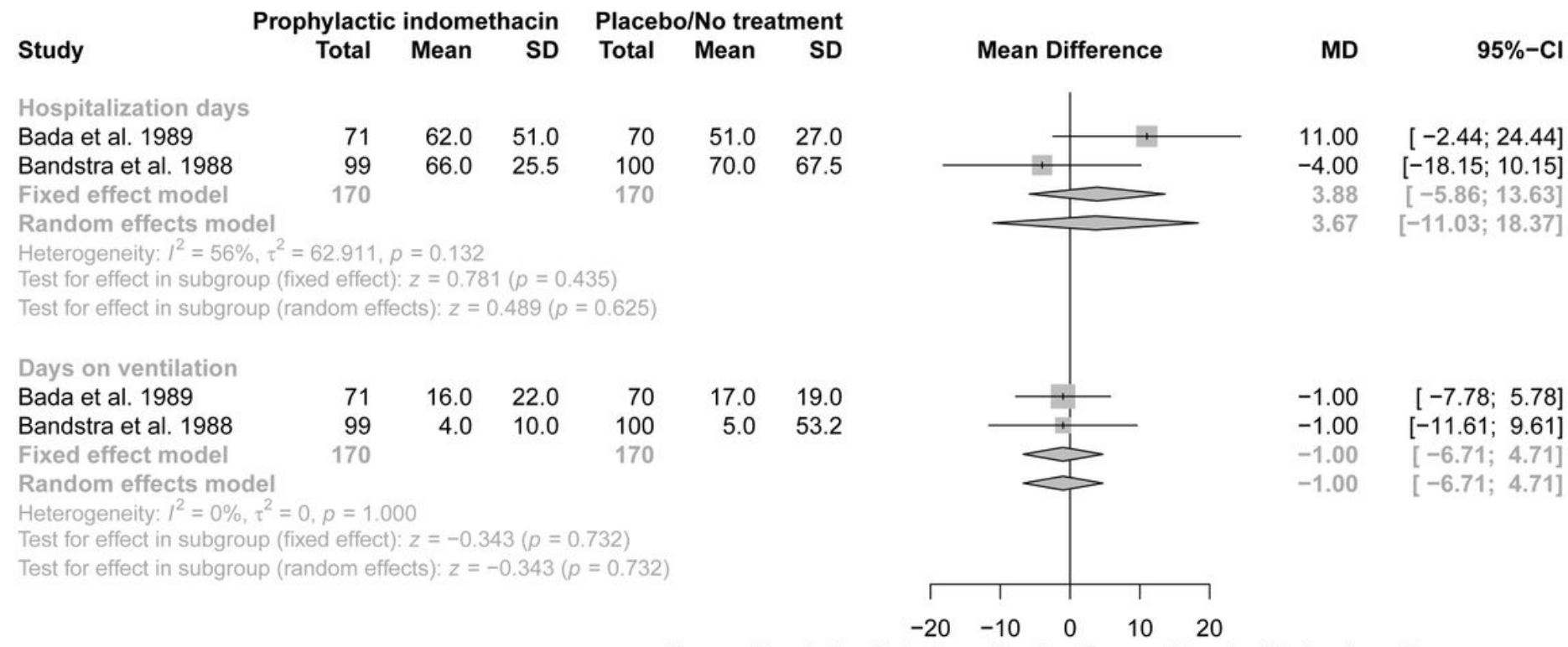

Favors Prophylactic indomethacin Favors Placebo/No treatment

Figure 8

Forest plot for hospitalization outcomes. 


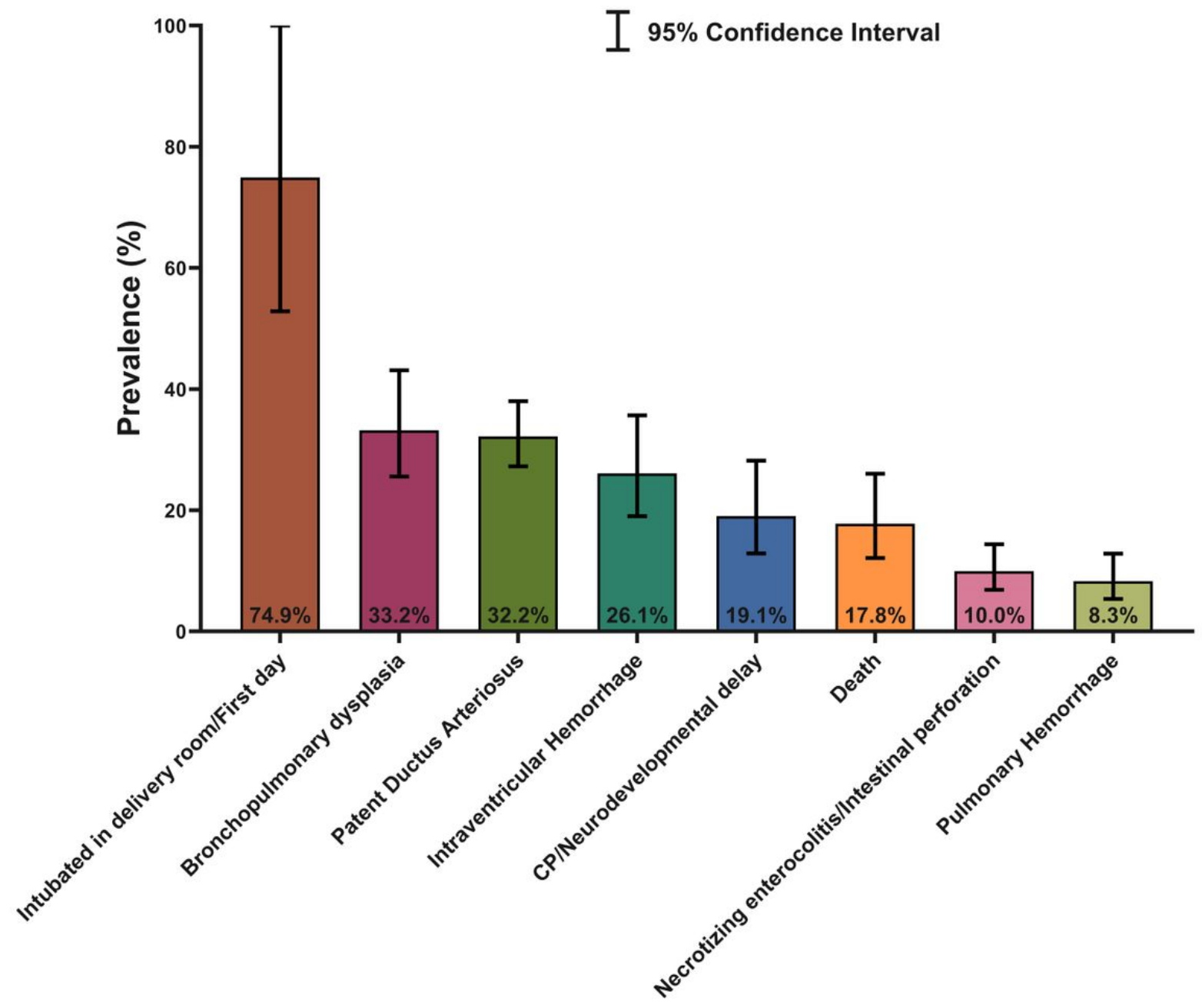

Figure 9

Forest plot for prevalence of different outcomes in prophylactic indomethacin group.

\section{Supplementary Files}

This is a list of supplementary files associated with this preprint. Click to download.

- thmanuscriptPRISMAchecklist.docx 